\title{
Extending the Pressure Limit for Turbomolecular Pump up to 133 Pa by using Conductance-Reducer and Measuring the Pressure Differences in Vacuum Chamber
}

\author{
S. S. Hong ${ }^{a *}$, Wakil Khan ${ }^{a, b}$, S. W. Kang ${ }^{a}$, J. Y. Yun ${ }^{a}$, and Y. H. Shin ${ }^{a}$ \\ ${ }^{a}$ Vacuum Technology Center, KRISS, Daejeon 305-340 \\ ${ }^{b}$ University of Science and Technology (UST), Daejeon 305-333
}

(Received December 14, 2009, Revised January 19, 2010, Accepted January 20, 2010)

\begin{abstract}
A dynamic flow system has been developed which can be used for vacuum gauge calibration by comparison method - a calibration method in which the reading of the gauge under calibration is compared to another calibrated vacuum gauge called the "secondary standard" - and other vacuum-related experiments. The chamber of the calibration system is pumped by a turbomolecular pump (TMP), backed by a scroll pump. As maximum acceptable pressure at the inlet of a TMP is $0.1 \mathrm{~Pa}$, above which the TMP decelerates, the pumping speed decreases and it becomes more difficult to adjust pressure under such circumstances. In the present work, high pressures of up to $133 \mathrm{~Pa}$ have been generated in the chamber of the newly developed dynamic flow control system by installing a well-designed conductance-reducer in the by-pass line and, at the same time, operating the TMP in safe mode. In addition, the gas flow and pressure distribution within the chamber have been investigated for the entire pressure range $(0.1 \mathrm{~Pa} \sim 133 \mathrm{~Pa})$ while generating pressure dynamically. Maximum deviations in pressure (1.6\%) were observed at point $\mathrm{C}$ on the chamber, which is close to the gas inlet port on the top of the chamber.
\end{abstract}

Keywords : Vacuum chamber, Pressure differences, Pressure limit, Conductance-reducer

\section{INTRODUCTION}

Vacuum technology is one of the established advanced technologies of the present age. The extent to which vacuum contributes to progress in scientific research and in technology of manufacturing has increased markedly in recent decades. Its applications in the large machines of particle physics and in fabrication of microelectronics devices are just two of many. For most of industrial as well as researchrelated fields, the users of vacuum technology rely on clean vacuum and prefer to turbomolecular pump over other vacuum pumps in the high vacuum range.

There is a wide range of applications of turbomolecular pumps (TMP) in industrial as well as research-related set-ups. It may be found, in various literatures, that a TMP can be used for stable pumping at vacuum chambers (e.g. in vacuum gauge calibration systems, accurate measurement of pressure differences etc.) up to an inlet pressure of approximately $0.1 \mathrm{~Pa}$. However, above this pressure, a calibration system with configuration in which the

* [E-mail] sshong@kriss.re.kr 
TMP is directly attached to the calibration chamber can not work properly. In this connection, a dynamic flow control system has been developed by Korea Research Institute of Standards and Science (KRISS) for vacuum gauge calibration by comparison method and other vacuum-related experiments in the full range of medium vacuum $(0.1 \mathrm{~Pa} \sim 133 \mathrm{~Pa})$. The system is equipped with a high vacuum pumping system (TMP of pumping speed $560 \mathrm{l} / \mathrm{s}$ for nitrogen backed by a scroll pump of pumping speed $300 \mathrm{l} / \mathrm{min}$ ), various types of vacuum measuring transducers and mass flow controllers (MFCs). High pressures of up to $133 \mathrm{~Pa}$ can be generated in the chamber of the system without affecting the performance of the TMP during continuous gas flow. This limit of high pressure was achieved by installing a conductance-reducer (CR) in the by-pass line between the chamber and the high vacuum pumping unit. It is worth mentioning that before installation, dimensions of the $\mathrm{CR}$ were properly estimated for generation of the desired pressure range. In addition, pressure differences within the chamber were also measured for the entire range of $0.1 \mathrm{~Pa} \sim 133 \mathrm{~Pa}$. This type of arrangement and measured pressure distribution will be much useful for generating pressures and calibrating vacuum gauges in the full range of medium vacuum during continuous gas flow.

\section{THEORY}

Analysis of vacuum system characteristics is based on the assumption that molecular velocity distribution is Maxwellian and their flux intensities are isotropic. The assumptions have been confirmed in many experiences [1]. The kinetic theory of gases provides a straightforward relationship between the number density of molecules and pressure in such cases [2]. However, the isotropic state is disturbed by the dynamic molecular flow of gas resulting from localized or distributed (usually both) sinks and/or sources. Depending on their contribution to the process, these sources and/or sinks cause nonuniform and non-isothermal gas flow in the pumped vessel. Industrial vacuum equipment subject to dynamic working conditions does not permit isotropic gas conditions at reduced degree of rarefaction [2]. Such systems are termed as "nonisotropic" systems. The system under consideration is a nonisotropic system working in the medium vacuum range $(0.1 \mathrm{~Pa}$ $133 \mathrm{~Pa}$ ) where pressure is generated dynamically.

With the active development of semiconductor fabrication technology, dilute gas flow phenomena are attracting attention recently [3] for which so many vacuum systems are needed [4]. In vacuum processes, like fabrication of semiconductor devices, calibration of vacuum gauges, accurate measurement of pressure, etc the pressure in the chamber is generated dynamically. The throughput of the calibration gas is introduced into the chamber through a fine control variable leak valve and pumped continuously by a pumping system. The pressure in the chamber is then determined by the equilibrium between the gas flow in and the gas flow out. As regions of the chamber act as sources and sinks for the gas flow, a non-uniform distribution of pressure occurs over the whole chamber [5]. Non-uniform gas distribution means specifically that if the gas characteristics at a point in a system are measured or established, these characteristics differ at other points in the system and such gas is often non-Maxwellian [6]. During dynamic gas flow, there are two sources of non-equilibrium and the pressure non-uniformity in the chamber: inlet of the gas and its sink in the pump [7]. Many researchers including Repa et al and G. Horikoshi et al [5, 8]have measured pressure differences during dynamic gas flow.

In order to suppress the influence of gas source and sink, the chamber has to have a suitable shape, it has to be sufficiently large, the gas after admission 
should be scattered by impinging on the walls, etc. [7]. Chambers of spherical or cylindrical shape are used for this purpose [5]. Although the large volume of the calibration chamber smooths the pressure fluctuations, the pressure is not easily controlled, affecting the pumping speed of the TMP. In order to control the pressure and, at the same time, run the TMP in safe mode the $\mathrm{CR}$ arrangement is more effective in this case.

As calibration gas is delivered through mass flow controllers (MFCs) that measure and control the flow of a particular gas ( $\mathrm{N}_{2}$ in our case), the gas flow pumped by the pumping system is necessary to be calculated for generating the desirable pressure range $(0.1 \mathrm{~Pa} \sim 133 \mathrm{~Pa})$. In order to know the quantity of gas flowing out of the chamber, we have to calculate the throughput, and hence, conductance of the path (CR) which in turn can be used for calculating the dimension of the required $\mathrm{CR}$.

Let $P_{U}$ be the upstream pressure in the vacuum chamber which is connected to the TMP through a short duct called the conductance-reducer (CR). On the other side of the duct there is a small volume in which the downstream pressure $P_{D}\left(P_{D}<P_{U}\right)$ is determined by the TMP as shown in Fig. 1 while the short duct (conductance-reducer) is made in a copper

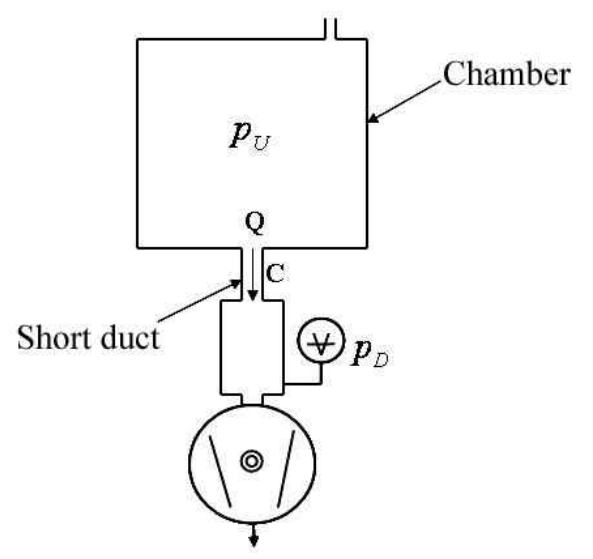

Figure 1. Flow of gas through a short duct: $P_{U}-$ Upstreampressure, $P_{U}$ - Downstream pressure, $\mathrm{Q}$ - Throughput, C - Conductance. disc as given below in Fig. 2.

The throughput at the inlet of TMP with $P_{D}=0.1$ $\mathrm{Pa}$ and $\mathrm{S}=560 \mathrm{l} / \mathrm{s}$ (for $\mathrm{N}_{2}$ ) is given by:

$$
\mathrm{Q}=5.6 \times 10^{-2} \mathrm{~Pa} \cdot \mathrm{m}^{3} \cdot \mathrm{s}^{-1}
$$

In order to generate maximum pressure of $133 \mathrm{~Pa}$ in the chamber, the corresponding conductance for a pressure difference of $132.9 \mathrm{~Pa}\left(P_{U}-P_{D}=133-0.1\right.$ $=132.9 \mathrm{~Pa}$ ) will be:

$$
\mathrm{C}=4.2 \times 10^{-4} \mathrm{~m}^{3} \cdot \mathrm{s}^{-1}
$$

This is the required conductance $C$ of the $\mathrm{CR}$ necessary in the by-pass line for generation of the desired pressure range $(0.1 \sim 133 \mathrm{~Pa})$. By using this conductance, we can estimate the required dimension of the CR. Some simple calculations in this connection are given below.

Formula for the conductance of a long cylindrical tube in the viscous flow regime is described by the following [9]:

$$
C=\frac{\pi D^{4}}{128 \eta L} \frac{p_{U}+p_{D}}{2}
$$

Where $\mathrm{D}$ and $\mathrm{L}$ are the diameter and length of the tube with $n$ as viscosity of gas which for nitrogen gas at room temperature is $1.75 \times 10^{-5} \mathrm{~Pa} \cdot \mathrm{s}^{-1}$. The value for conductance in equation (3) is corrected for a short circular tube with correction factor $k$ as [10]:

$$
C=\frac{\pi D^{4}}{128 \eta L k} \frac{p_{U}+p_{D}}{2}
$$

In order to check the value of $\mathrm{k}$, we should calculate the value of Reynolds number (Re)which is

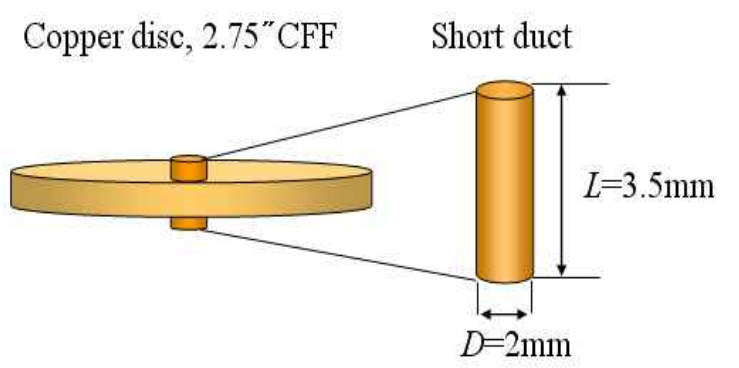

Figure 2. Conductance-reducer (CR): copper disc with short duct used as the gasket in one of the flange. 
given by:

$$
\operatorname{Re}=\frac{4 Q M}{\pi R T \eta d}
$$

Putting the values; for nitrogen gas $\mathrm{M}=28$ $\mathrm{kg} \cdot \mathrm{k} \cdot \mathrm{mol}^{-1}, \quad \eta=1.75 \times 10^{-5} \mathrm{~Pa} \cdot \mathrm{s}^{-1}$ with $\mathrm{T}=293 \mathrm{~K}$, $\mathrm{R}=8.314 \mathrm{~J} \cdot \mathrm{k} \cdot \mathrm{mol}^{-1}$ and $\mathrm{d}=2 \mathrm{~mm}$ of the $\mathrm{CR}$, the value of $\mathrm{Re} \approx 23.5$ and this value varies in the interval $0.3 \sim 190$ depending on dimensions of the $\mathrm{CR}$ and pressures in the system. Under these circumstances, the value of $\mathrm{k}$ is close to 1 (i.e. in between 0.71 and 1.00) and we can use the formula for the long tube as well which is given in equation (3). Putting values in equation (3) we get $\mathrm{L}=3.5 \mathrm{~mm}$ which is same as actual dimension of the installed CR. This CR is used between the chamber and TMP instead of a copper gasket in one of the flange connection as shown in Fig. 3. With this arrangement, the maximum continuous inlet pressure $P_{D}$ could not increase from the tolerable value of the TMP and its operation remains safe.

In order to describe the type of gas flow, it is

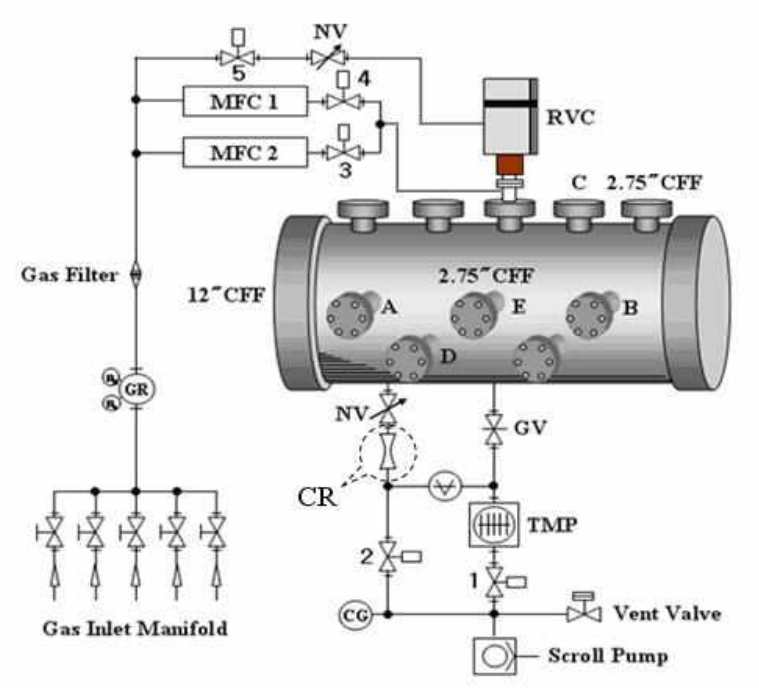

Figure 3. Schematic diagram of flow-control system: RVC - Regulated valve controller, NV-Needle valve, GR - Gas regulator, CG - Convectron gauge, 1-5 Pneumatic valves, $\mathrm{CR}-\mathrm{Con}-$ ductance-reducer. convenient to use the Knudsen number [11] $\mathrm{Kn}=\lambda / \mathrm{d}$ with $\lambda$ as mean free path of the gas molecules and $\mathrm{d}$ as characteristic dimension of the vacuum component. On the basis of Knudsen number, gas flows can be classified as [12]:

$$
\begin{aligned}
& \mathrm{Kn}<0.01 \text { Viscous flow } \\
& \mathrm{Kn}>0.5 \text { Molecular flow }
\end{aligned}
$$$$
0.01<\mathrm{Kn}<0.5 \text { Transitional flow }
$$

For a gas consisting of molecules of same diameter, the mean free path can be calculated from [13]:

$$
\lambda=\frac{3.107 \times 10^{-24} \mathrm{~T}}{\mathrm{P}_{\mathrm{m}}{ }^{2}}
$$

Where $\mathrm{T}(\mathrm{K}), \mathrm{P}(\mathrm{Pa})$, and $\delta_{\mathrm{m}}(\mathrm{m})$ are temperature, pressure and diameter of the gas molecules respectively. For nitrogen gas the value of $\delta_{\mathrm{m}}$ is $3.78 \times 10^{-10} \mathrm{~m}$. By using equation (6) we can calculate the mean free path and, hence, the values of Knudsen number in a vacuum component which, in turn, can give us information about the type of prevailing gas flow.

\section{EXPERIMENTAL SET-UP}

A flow-control system (Fig. 3) has been developed with a large vacuum chamber and a high vacuum pumping system separated by a pneumatically controlled 8" CF flange gate valve (GV). A Conductance-reducer (CR) is installed in the by-pass line and a full range gauge (FRG, PFEIFFER Vacuum; Type PKR 251) which can read pressure from atmosphere to high vacuum $\left(10^{5} \sim 10^{-7} \mathrm{~Pa}\right)$ is attached to the chamber. During experiment, the main evacuation valve remains closed and the chamber is pumped through the by-pass line. Two mass flow controllers (MFCs 1 and 2) are installed on top of the chamber with flow controls of 1 slm and 3 $\mathrm{sccm}$ respectively $\left(1 \mathrm{sccm}=1.69 \times 10^{-3} \mathrm{~Pa} \cdot \mathrm{m}^{3} \cdot \mathrm{s}^{-1}\right)$. Precise gas throughputs can be injected to the chamber through these mass flow controllers. The 
total volume of the chamber is $36.65 \mathrm{l}$ which is covered with a heating jacket (bakeable up to $200^{\circ} \mathrm{C}$ ). After installing the $\mathrm{CR}$, the chamber was bakeout such that the temperature was gradually increased to $150^{\circ} \mathrm{C}$ in $3 \mathrm{hrs}$, maintained constant for next $24 \mathrm{hrs}$ and then gradually decreased to room temperature in 6 hrs. After baking, the system was operated for about $24 \mathrm{hrs}$ and achieved a base pressure less than $6 \times 10^{-6} \mathrm{~Pa}$.

The system also has the facility of automatic control of gas flow through a Regulated Valve Controller (RVC) and with 5 manifold inlets but in this case the gas flow to the chamber is controlled through MFCs only. The pressure of the manifold was adjusted at $100 \mathrm{kPa}$ by an auto regulated valve and remained constant throughout the experiment. All the equipment including pumps, gauges, flow meters and valves etc are fully computer-controlled.

In order to measure pressure, five capacitance diaphragm gauges (CDGs) of $133 \mathrm{~Pa}$ range were installed on the chamber (shown in Fig. 3) as the capacitance sensing technique resulting in a high degree of pressure sensitivity, can be used conveniently in medium vacuum, are easy to use and have good accuracy and resolution as well [14-16]. All the CDGs were well calibrated on ultrasonic interferometer manometer (UIM) whose working principle is somewhat different from the traditional mercury manometer. The difference in heights due to the difference in pressure between the mercury columns is measured using ultrasonic interferometry [17-19]. These CDGs were, then, installed after one week of calibration, on the chamber at locations A, B, C, D and $\mathrm{E}$ where $\mathrm{CDG}-3$ is located at the central position E. The data for all the CDGs were recorded at the same time. The same type of gas $\left(\mathrm{N}_{2}\right)$ was used as the test gas, either for calibration of $\mathrm{CDGs}$ or to generate pressure inside the vacuum chamber. The measurements were performed in a sequence of increasing pressure ranging from $0.1 \mathrm{~Pa}$ to $133 \mathrm{~Pa}$. There are no changes in volume, geometry and temperature of the chamber. Room temperature was controlled at $(20 \pm$ $0.5){ }^{\circ} \mathrm{C}$.

\section{RESULTS AND DISCUSSION}

Fig. 4 shows the generated pressure versus time graph for the chamber when GV is closed at base pressure $<6 \times 10^{-6} \mathrm{~Pa}$ and the calibration gas throughput is delivered into the chamber. In the range 0.03 to $12.0 \mathrm{sccm}$ of the calibration gas, the upstream pressure $\left(P_{U}\right)$ varies from $<1 \mathrm{~Pa}$ to $133 \mathrm{~Pa}$ by a continuous pumping of TMP through $\mathrm{CR}$. It is evident that after each input value of gas flow, the $P_{U}$ becomes constant within a time of about $20 \sim 25$ minutes and the data were recorded after each 30 minutes. Ten data points were noted in the entire pressure range $(0.1 \mathrm{~Pa} \sim 133 \mathrm{~Pa})$ and the experiment was repeated four times under similar conditions. The upstream pressure $P_{U}$ and downstream pressure $P_{D}$ as a function of gas flow are shown in Fig. 5. The maximum downstream pressure generated at the inlet of the TMP is $<1 \mathrm{~Pa}$ as shown on the right scale of Fig. 5 whereas on the other side of the $\mathrm{CR}$, the

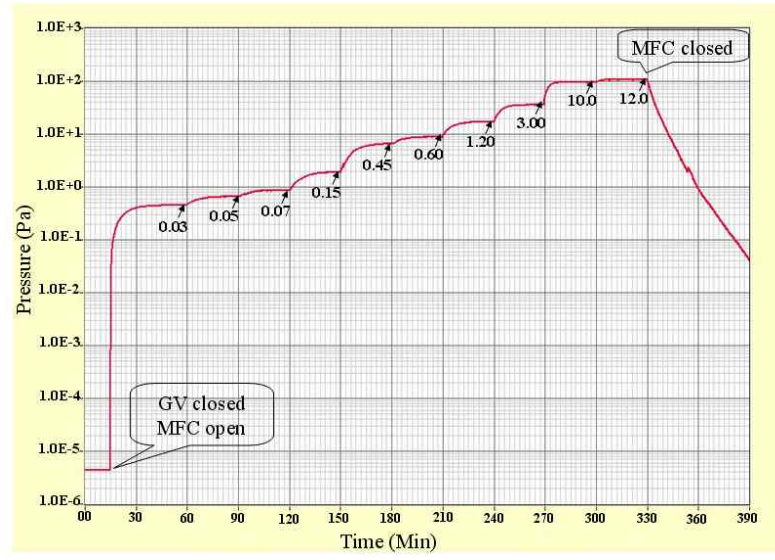

Figure 4. Generated pressure vs. time in response to changes in gas flow pumped by TMP through conductance-reducer. Arrows show different values of gas-flow in $\mathrm{sccm}$. 


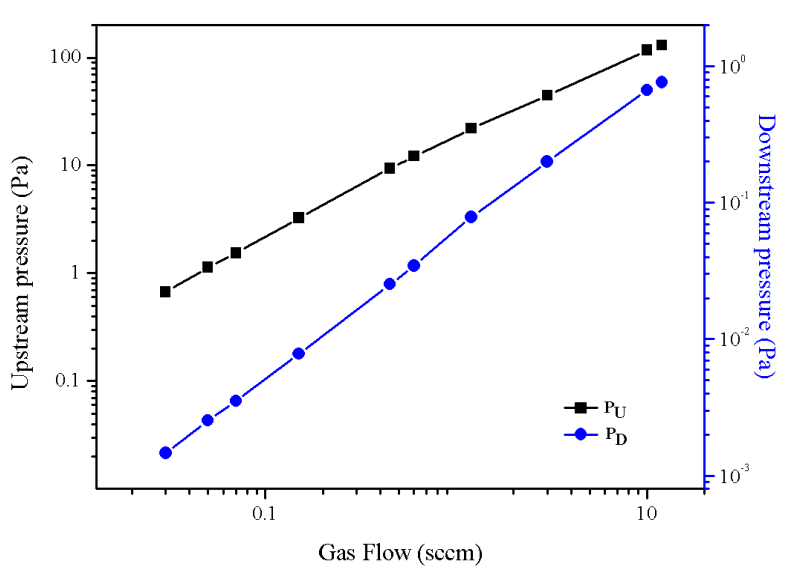

Figure 5. Up-stream $\left(P_{U}\right)$ and downstream $\left(P_{D}\right)$ pressures as a function of gas flow.

Table 1. Mean free path along with Knudsen number for different values of the average generated pressures in the chamber.

\begin{tabular}{c|c|c|c}
\hline \hline S. No & $\begin{array}{c}\text { Average Pressure } \\
(\mathrm{Pa})\end{array}$ & $\begin{array}{c}\text { Mean Free Path } \\
(\lambda)\end{array}$ & $\begin{array}{c}\text { Knudsen Number } \\
(\mathrm{Kn})\end{array}$ \\
\hline 1. & 0.670 & 0.0095 & 0.0372 \\
\hline 2. & 1.131 & 0.0056 & 0.0221 \\
\hline 3. & 1.534 & 0.0041 & 0.0162 \\
\hline 4. & 2.00 & 0.0032 & 0.0125 \\
\hline 5. & 3.269 & 0.0019 & 0.0070 \\
\hline 6. & 9.340 & 0.0006 & 0.0026 \\
\hline 7. & 12.176 & 0.0005 & 0.0020 \\
\hline 8. & 22.005 & 0.0002 & 0.0011 \\
\hline 9. & 44.615 & 0.00014 & 0.0005 \\
\hline 10. & 117.454 & 0.000054 & 0.00021 \\
\hline 11. & 130.781 & 0.0000489 & 0.00019 \\
\hline
\end{tabular}

maximum upstream pressure generated in the vacuum chamber is about $133 \mathrm{~Pa}$ (left scale in Fig. 5).

In Table 1 the values of mean free path $\lambda$ along with Knudsen number $\mathrm{Kn}$ are given for different values of the average generated pressures in the chamber as calculated from equation (6). From the table it can be seen that in the pressure range 0.67 $\mathrm{Pa}$ to $2.0 \mathrm{~Pa}$, the value of Knudsen number varies from 0.372 to 0.0125 , showing that the gas flow in the chamber is transitional.

However, as pressure rises above 2.0 $\mathrm{Pa}$, the gas

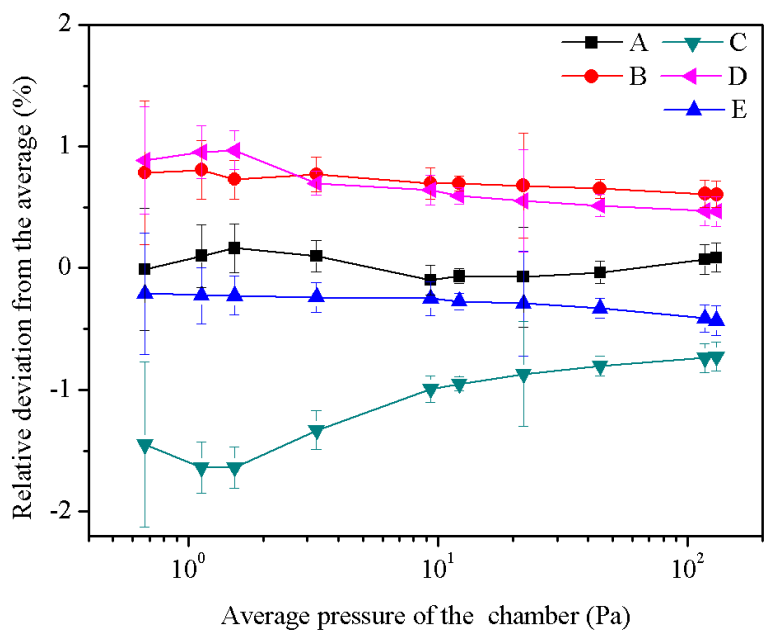

Figure 6. Relative deviation of pressure differences at various locations ( $\mathrm{A}, \mathrm{B}, \mathrm{C}, \mathrm{D}$ and $\mathrm{E}$ ) on the vacuum chamber versus the average pressure. The error bars show the relative standard deviation of the measurement values of pressure.

flow gradually changes to viscous laminar as the value of $\mathrm{Kn}$ is becoming less than 0.01. This flow change has great impact on pressure deviations at various locations within the chamber. In order to calculate the relative deviations from the average, the following relation is used:

$$
\text { Relative deviation }=\frac{p_{\text {ind }}-\bar{p}}{\bar{p}}
$$

Where $\mathrm{P}_{\text {ind }}$ is the individual pressure of each CDG at a particular throughput of the calibration gas and $\bar{p}$ is the average pressure of all the CDGs at that particular throughput to the chamber. The results of pressure distribution are given in Fig. 6. As discussed earlier, up to $2.0 \mathrm{~Pa}$, the flow within the chamber is intermediate which is composed of molecular as well as viscous laminar flow with the latter dominating the total flow as pressure gradually rises in the chamber. However, above $2.0 \mathrm{~Pa}$ the flow shifts towards the viscous laminar which is more regular (continuous) flow than the intermediate. That is why during the viscous laminar flow, the total deviations are comparatively less than deviations in the intermediate flow. For example, at 
Extending the Pressure Limit for Turbomolecular Pump up to $133 \mathrm{~Pa}$ by using Conductance-Reducer and Measuring the Pressure Differences in Vacuum Chamber

pressure value of $1.534 \mathrm{~Pa}(\mathrm{Kn}=0.016$, intermediate flow), the maximum total deviations are $2.60 \%$ (0.968 $\%$ above and $-1.637 \%$ below the zero line). However, at about $10 \mathrm{~Pa}, \mathrm{Kn}=0.0026(<0.01$, viscous laminar flow), the total deviations are $1.69 \%$ which at higher pressures of $133 \mathrm{~Pa}$ reaches the minimum total value of $1.33 \%(0.605 \%$ above and $-0.728 \%$ below the zero line), showing a significant decrease in pressure deviations. A comparison of pressure deviations in the entire pressure range for both the states, transitional and viscous laminar shows about $50 \%$ low deviations for the latter type of flow regime. It is worth mentioning here, that the typical calibration drift for CDGs of the same type used is $0.5 \%$ per year [20]. Since these CDGs were installed on the system after just one week of calibration, the deviations in pressure are real and arise due to pressure non-uniformities. Individual relative deviations of locations $\mathrm{A}, \mathrm{B}, \mathrm{D}$ and $\mathrm{E}$ are less than $1 \%$. Point $\mathrm{D}$ is located down level of the chamber near the outlet whereas point $\mathrm{A}, \mathrm{B}$, and $\mathrm{E}$ are located at the central horizontal line of the chamber as shown in Fig. 3. The error bars shown in Fig. 6 are relative standard deviations corresponding to the measured values of pressures. The error is less than $0.7 \%$ in all cases. This error represents the repeatability of the generated pressure as a function of gas flow.

\section{CONCLUSIONS}

The present work shows that it is possible to extend the pressure range generated in a vacuum chamber, pumped with a TMP, by means of a conductance reducer in the by-pass line. By using such arrangement a pressure of $133 \mathrm{~Pa}$ can be readily achieved in the chamber. This type of arrangement will be useful for vacuum gauge calibration systems and other vacuum-related experiments in the pressure range $0.1 \mathrm{~Pa} \sim 133 \mathrm{~Pa}$ where pressure is generated dynamically. In addition, it was observed that deviations in pressure distribution for the chamber were higher in the transitional flow regime than in the viscous flow. The large individual deviation in pressure $(1.6 \%)$ at point $\mathrm{C}$ can be attributed to its position as it is close to the gas inlet port but away from the pumping line in the chamber.

\section{ACKNOWLEDGEMENTS}

This work is financially supported by Ministry of Education \& Science Technology through the Project of "Development of Advanced Industrial Metrology" at the Korea Research Institute of Standards and Science (KRISS).

\section{REFERENCES}

[1] Y. Tuzi, M. Kobayshi, and I. Arakawa, Proceedings of the ${ }^{14 \text { th }}$ International Symposium on Rarefied Gas Dynamics, Japan, 385 (1984).

[2] A. Berman, Total Pressure Measurement in Vacuum Technology, Academic Press, Inc. Orlando, Florida, 23 (1985).

[3] Wakil Khan, K. S. Hong, and S. S. Hong, J. Kor. Vac. Soc. 18, 403 (2009).

[4] J. H. Joo, H. B. Kim, and J. J. Kim, J. Kor. Vac. Soc. 17, 278 (2008).

[5] P. Repa, Z. Cespiro, L. Peksa, T. Gronych, and J. Tesar, Metrologia 36, 551 (1999).

[6] B. C. Moore, J. Vac. Sci. Technol. 6, 246 (1969).

[7] L. Peksa, T. Gronych, P. Repa, and J. Tesar, Vacuum 67, 333 (2002).

[8] G. Horikoshi, T. Kuroda, and Y. Oka, Vacuum 44, 617 (1993).

[9] V. Odnoralov, Revista Brasileira de Aplicacoes de Vacuo 24, 110 (2005).

[10] Edelmann Ch. and Wissensspeicher Vakuumtechnik, VEB Fachbuchverlag Leipzig, 72 (1985). 
[11] W. Jitschin and G. Reich, J. Vac. Sci. Technol. A, Vol. 9, 2752 (1991).

[12] Karl Jousten, Handbook of Vacuum Technology, Wiley-Vch Verlag GmbH \& Co. KGaA, 81 (2008).

[13] Armand Berman, Vacuum Engineering Calculations, Formulas, and Solved Exercises, Academic Press, Inc. 46 (1992).

[14] Richard W. Hyland and Charles R. Tilford, J. Vac. Sci. Technol. A3(3), 1731 (1985).

[15] W. Jitschin, Metrologia 39, 249 (2002).
[16] J. M. Hidalgo and J. L. de Segovia, Vacuum 82, 1503 (2008).

[17] S. S. Hong, Y. H. Shin, and K. H. J. Chung, J. Kor. Vac. Soc. 44, 1364 (2004).

[18] S. S. Hong, Y. H. Shin, and K. H. J. Chung, J. Vac. Sci. Technol. A 24, 1831 (2006).

[19] S. S. Hong, Y. H. Shin, and K. H. J. Chung, J. Kor. Vac. Soc. 5, 181 (1996).

[20] A. P. Miller, Metrologia 36, 617 (1999). 


\title{
확장한 진공용기 내부의 압력구배 측정 \\ 홍승수 ${ }^{a} *$ 와킬 칸 ${ }^{\mathrm{a} b} \cdot$ 강상우 $^{\mathrm{a}} \cdot$ 윤주영 $^{\mathrm{a}} \cdot$ 신용현 $^{\mathrm{a}}$ \\ a한국진공센터, 대전 305-340 \\ ${ }^{\mathrm{b}}$ 과학연합대학원(UST), 대전 305-333 \\ (2009년 12월 14일 받음, 2010년 1월 19일 수정, 2010년 1월 20일 확정)
}

\begin{abstract}
진공게이지의 비교교정 방법으로 교정이 가능하고-비교교정은, 2 차표준기라고 부르는 교정되어진 게이지와 교정할 다른 게 이지의 지시값을 읽어 비교는 방법- 다른 진공관련 실험을 할 수 있는 기체 유량 시스템을 개발하였다. 교정시스템에의 진공 용기는 터보분자펌프(TMP)에 의해서 배기하고, 후면에 스크롤펌프를 배치하여 배기시스템을 꾸몄다. 터보분자폄프의 최대 허용가능 압력은 폄프의 주입구에서 $0.1 \mathrm{~Pa}$ 까지이며, 이보다 압력이 높아지면 배기속도가 감소하며 압력대 이하의 환경을 조 절하기가 매우 어렵게 된다. 현재 $133 \mathrm{~Pa}$ 까지의 높은 압력을 발생시킬 수 있는 새롭게 개발된 기체유량조절시스템은 바이패 스 라인에 맞도록 설계된 컨덕턴스-리듀서를 설치하여 터보분자폄프를 안전하게 운용할 수 있도록 하였다. 추가로 진공용기 안에 전체압력 범위 $(0.1 \mathrm{~Pa} \sim 133 \mathrm{~Pa})$ 의 압력을 생성하며 기체 주입과 압력구배를 연구하였다. 압력의 최대 편차는 용기의 위쪽 방향에 위치한 가스 주입구에서 가까운 위치 C에서 $1.6 \%$ 로 나타났다.
\end{abstract}

주제어 : 진공 용기, 압력차이, 압력한계, 콘덕턴스 reducer

\section{* [전자우편] sshong@kriss.re.kr}

